\title{
Arterial Hypertension and Diabetes Mellitus as Risk Factors in the Evolution of Patients with COVID-19
}

\author{
Carlos Miguel Campos Sanchez*, Jose Carlos Garcia Roque, Liz Greit Garcia Rodriguez, \\ Laura Adalys Guillen Leon, Juan Miguel Garcia Velazquez, Isbety Acosta Escanaverino, \\ Daniel Rodriguez Hurtado
}

Health Faculty, Villa Clara University of Medical Sciences, Villa Clara, Cuba

Email address:

karlosk@nauta.cu (C. M. C. Sanchez)

${ }^{*}$ Corresponding author

\section{To cite this article:}

Carlos Miguel Campos Sanchez, Jose Carlos Garcia Roque, Liz Greit Garcia Rodriguez, Laura Adalys Guillen Leon, Juan Miguel Garcia Velazquez, Isbety Acosta Escanaverino, Daniel Rodriguez Hurtado. Arterial Hypertension and Diabetes Mellitus as Risk Factors in the Evolution of Patients with COVID-19. American Journal of Laboratory Medicine. Vol. 6, No. 2, 2021, pp. 22-26.

doi: $10.11648 /$ j.ajlm.20210602.12

Received: March 13, 2021; Accepted: April 6, 2021; Published: April 16, 2021

\begin{abstract}
COVID-19 is one of the most relevant pathologies in recent months, becoming one of the most deadly pandemics that the world has faced; Since the detection of the first cases in Wuhan (China) until today, the evolution of those infected has been a bit unpredictable, although without a doubt comorbidities such as Diabetes Mellitus (DM) and Arterial Hypertension (HTN) have been an essential link in fatality of clinical evolutions and the main cause of transfer to intensive care units. A bibliographic analysis was carried out, using the Scielo, Scopus, EBSCO and Google Academic databases, where information was obtained from twenty-two bibliographic references in order to determine the influence of arterial hypertension and diabetes as risk factors in the evolution of patients with covid 19. Patients diagnosed with COVID-19 who have hypertension and diabetes as a personal medical history are more likely to develop complications during the course of the disease and even die. The control and isolation of these patients is of special importance, taking into account the risk posed by presenting these pathologies. The research work carried out in Cuba maintains the control and knowledge of the health personnel of the state of vulnerable patients.
\end{abstract}

Keywords: Diabetes Mellitus, Arterial Hypertension, COVID-19

\section{Introduction}

Respiratory viral infections continue to emerge as a challenge for public health, some of the examples in the last two decades are the SARS-Cov (Severe Acute Respiratory Syndrome coronavirus) in 2002, in 2009 the H1N1 influenza and in 2012 the MERS- CoV (Middle East Respiratory Syndrome coronavirus). Last December 2019, the third new coronavirus emerged in the last 17 years, specifically in Wuhan Hubei province, China; named SARSCoV-2 (severe acute respiratory syndrome coronavirus 2) responsible for the disease named in February 2020 as COVID-19 by the World Health Organization (WHO).[1]

The recent global COVID-19 emergency caused by SARSCoV-2 was declared a pandemic by the World Health
Organization (WHO) on March 11, 2020. COVID19 is a severe acute respiratory syndrome caused by a new Coronavirus identified in the city of Wuhan, capital of Hubei province in China, in December 2019. The clinical manifestations of COVID-19 vary from an asymptomatic disease, to a severe condition with respiratory failure, multiorgan dysfunction, septic shock and death. The most common symptoms are fever, dry cough, and fatigue. However, some COVID-19 patients develop vomiting, diarrhea, and abdominal pain during the course of their illness. [2]

The appearance of epidemics is not something new in the history of humanity, but in recent years, we are witnessing epidemic outbreaks, many of them due to viruses, which cause social alarm. [3]

The reasons why these outbreaks have more impact are human reasons and derive from our way of life (living in big 
cities, more trips for leisure or business, commercial exchanges) and from the hyper information that exists where the mass media, formal or informal, they keep us updated minute by minute of the development of any event of global impact. [3]

This disease is spreading in Latin America, reporting its first cases at the end of February in Brazil, Mexico and Ecuador, and in April 201,977 cases were reported in this region. [4]

On March 11, 2020, the first three imported cases of the disease from Italy, detected in the municipality of Trinidad, in the Sancti Spiritus province, are notified in Cuba. [4]

As of February 21, 2021, 111,747,462 cases and a fatality of 2.21 have been reported in the world. Latin America, in turn, reports $50,263,114$ cases $(+183,516)$, representing $44.97 \%$ of the world's cases and a fatality of 2.36. Cuba, thanks to the measures taken by the national health system, maintains extremely low figures compared to other countries, 839 new cases were reported this day, for a total of 45,361 cases, only $1.98 \%$ of the patients studied by PCR (2 281712 samples) [5]

What is the influence of hypertensive and diabetic antecedents in the evolution of positive patients for covid 19 ?

Objective: To determine the influence of high blood pressure and diabetes as risk factors in the evolution of patients with covid 19 .

\section{Development}

Coronaviruses (CoVs) are a group of viruses that cause illnesses ranging from the common cold to serious infections. There are four main subgroups: alpha, beta, gamma, and delta.

Common human coronaviruses:

1) $229 \mathrm{E}$ (alpha coronavirus)

2) NL63 (alpha coronavirus)

3) OC43 (beta coronavirus)

4) HKU1 (beta coronavirus)

Other human coronaviruses:

MERS-CoV (the beta coronavirus that causes Middle East Respiratory Syndrome, or MERS) [1]

According to the evidence available to date, the virus spreads mainly from person to person through close contact, even among health workers who care for patients with COVID-19, which would be consistent with what is known on other similar pathogens such as SARS and MERS-CoV.

Transmission can be direct by small droplets (gout transmission) that occur when a person coughs or sneezes. These droplets can reach the mouth or nose of people who are less than 1.8 meters, mainly 1 meter, who can inhale them when breathing.

An indirect form of transmission occurs when these droplets remain on objects or surfaces and the individual touches them and then touches their eyes, mouth or nose with contaminated hands (contact transmission). Studies have been carried out with taking environmental samples in the rooms of patients with COVID 19 and it was observed that the contamination occurs mainly on the surfaces closest to the patients and no particles suspended in the air were detected. This means in principle that COVID 19 is not transmitted through the air, but through droplets. [6]

\subsection{Arterial Hypertension}

Nowadays, arterial hypertension (HTN) is one of the most common diseases that affect human health, being an important pathology and risk factor for other diseases. [7]

(HT) is a chronic disease in which the pressure with which the heart pumps blood to the arteries increases, so that it circulates throughout the body. [8]

Hypertension is considered a disease of multifactorial origin, among them heredity, environmental, hemodynamic and humoral factors. The role of atrial natriuretic peptide, a substance related to changes in atrial pressure and hypotension, neuropeptic G, which behaves as a cotransmitter of norepinephrine and can participate in the physiological control of vascular tone and release in situations of stress. Active substances such as prostacyclin, nitric oxide or factor derived from the endothelium with vasodilator actions and a peptide with great vasoconstrictor action are produced in the vascular endothelium; they intervene directly or by interaction with other cells on vascular tone. [7]

SARS-CoV-2 enters the cell using as receptor the angiotensin converting enzyme 2 (ACE2), a membrane exopeptidase present mainly in the epithelium of the airway, lung parenchyma, vascular endothelium, brain, kidney, heart, testicular tissue and intestine. Therefore, patients with SARSCoV-2 may have multisystem involvement. [9]

The foregoing generated great expectations regarding the potential risk of using two groups of antihypertensive drugs in patients with COVID-19. These groups of antihypertensive drugs are the angiotensin converting enzyme (I-ACE) inhibitors and the angiotensin II AT1 receptor antagonists (ARBs), which have been used for decades in the treatment of hypertension and heart failure. and both with strong evidence on the benefit in cardiovascular morbidity and mortality in these patients. [10]

Angiotensin converting enzyme (I-ACE) inhibitors and angiotensin receptor blockers (ARA II) may overexpress ACE 2, leading to the hypothesis that this effect may be increased.

In the study by Li et al., Published in JAMA Cardiology, no association was found in patients with hypertension and hospitalized for COVID-19, between the use of I-RCT / AIIRA with severity or mortality from COVID-19 in this group of patients. [10]

Mehra et al. Found similar results to previous studies, without finding a potential deleterious association of the use of I-RCT or ARA II with in-hospital mortality and the use of I-RCT / AIIRA. Mancia et al. In Lombardy, Italy, report a study of 6,272 cases and 30,759 controls, in which no evidence was found that the use of I-RCT or ARA II affected the risk of COVID-19. [10]

The evidence available at the moment suggests that people with chronic non-communicable diseases (NCDs) are at greater risk of serious complications (hospitalization in intensive care, need for use of mechanical ventilation and 
death) from COVID-19 infection. [11]

It has been reported that the severity of the clinical presentation of COVID-19 depends on several genetic factors (polymorphisms in the ACE2 and TMPRSS2 genes and nongenetic ones (advanced age, male gender, and presence of comorbidities. In particular, several investigations have contributed evidence of association between severe forms of COVID-19 and the presence of a personal pathological history of hypertension, diabetes mellitus, or chronic kidney disease. [12]

A retrospective study carried out in Wuhan, showed that the patients who did not survive had a mean age of 69 years and hypertension was the most frequent comorbidity with $48 \%$ followed by diabetes with $31 \%$ and ischemic heart disease with $24 \%$. In Italy, the Italian Health Institute reported in March that in 2003 patients with a mean age of 79.5 and a mean of 2.7 comorbidities per patient, as in China, arterial hypertension was the most prevalent comorbidity with $76.1 \%$, followed by diabetes mellitus with $35.5 \%$ and ischemic heart disease with $33.3 \%$. The high prevalence of hypertension among older adults is a recognized fact. [13]

Patients with any form of heart disease can have a $10.7 \%$ mortality rate in COVID-19 and hypertension of $6 \%$. [13]

The presence of comorbidities in severe cases of COVID19 has been widely demonstrated. Data from the onset of the pandemic in China show that, while mortality without comorbidities was $0.9 \%$, it increased to $10.5 \%$ with cardiovascular disease, $7.5 \%$ with diabetes, and $6.3 \%$ with obstructive pulmonary disease chronic, 6\% with arterial hypertension and $5.6 \%$ with cancer. In an analysis of 1,590 patients admitted to different cities in China, the presence of a comorbidity increased the risk of a combined end point of ICU admission, MRA, or death (adjusted for age) by $\sim 80 \%$ (HR $1.79,95 \%$ CI $1.16-2.77$ ) and the presence of two or more comorbidities in more than 2 times $(2.59,95 \%$ CI 1.61 4.17). The most common risk factors were high blood pressure and diabetes, both of which increased the risk by $60 \%$. A meta-analysis, also from China, which included 8 studies with 46,248 patients estimated that patients with arterial hypertension had $>2$ times the risk of suffering from severe forms of COVD-19 and those with cardiovascular disease more than three. In the Lombardy cohort of severe cases admitted to ICU, arterial hypertension (49\%), cardiovascular diseases $(21 \%)$ and diabetes $(17 \%)$ were the most frequent comorbidities, more than cancer $(8 \%)$ and that chronic obstructive pulmonary disease (4\%). The study stratified the cohort by the presence or absence of hypertension and hypertensive patients had higher mortality ( $65 \%$ vs $40 \%, p<0.001)$. However, this data should be taken with caution since $58 \%$ of the patients were still hospitalized at the time of the analysis, in addition to the fact that the hypertensive patients were older. Also in Italy, the analysis of a group of 355 deceased patients in whom a detailed clinical history was available, confirms the association of mortality with cardiovascular diseases and diabetes; $30 \%$ had coronary artery disease, $24.5 \%$ atrial fibrillation, $9.6 \%$ had a history of stroke, and $39.5 \%$ were diabetic. Only 3 patients $(0.8 \%)$ had no underlying disease and $3 / 4$ parts had 2 or more comorbidities. In the cohort of cases hospitalized in New York, arterial hypertension (56\%), obesity (41.7\%) and diabetes $(33.8 \%)$ were the most frequent comorbidities. [14]

$80.8 \%$ of those who died in Colombia had some comorbidity, similar to what has happened in other countries. This confirms that COVID-19 affects more people with an adverse health history. Of the total deaths up to May 7, 2020 in Colombia, 4 out of 10 people suffered from arterial hypertension. Reviewing the publication by Zhou et al, from Wuhan (China), we found a retrospective cohort in which 191 patients were included, of which up to $48 \%$ had comorbidities, hypertension being the most common (58 patients, 30\%) [15]

To date, there is no treatment or specific effective vaccine for COVID-19, with prevention being the most important measure. [11]

\subsection{Mellitus Diabetes}

Diabetes mellitus is a syndrome characterized by generalized metabolic disorders in which the dominant factor is chronic hyperglycemia. Inadequate glycemic control favors the development of acute and chronic complications, increases the risk of disability and affects the quality of life of patients. [16]

Between $3 \%$ and $4 \%$ of the world's population is sick with diabetes, a condition that occurs when the pancreas cannot make enough insulin or when it fails to act in the body, because the cells do not respond to its stimulus, which leads to a significant risk towards other diseases, thus reducing the quality of life by an average of 10 or more years. According to the World Health Organization (2018), 70\% of people with diabetes live in low- and middle-income countries; in Mexico approximately 425, 345 inhabitants suffer from diabetes. [17]

In general, people with diabetes face higher risks of complications when it comes to viral infections such as influenza, flu, and that is likely to apply to COVID-19 as well. [18]

The severity of the clinical presentation of COVID-19 has been reported to depend on several genetic factors (polymorphisms in the ACE2 and TMPRSS2 genes) and nongenetic factors (advanced age, male gender, and the presence of comorbidities. In particular, several investigations have provided evidence of association between severe forms of COVID-19 and the presence of a personal pathological history of hypertension, diabetes mellitus or chronic kidney disease. The identification of comorbidities associated with the severe clinical presentation of COVID-19 is important for the appropriate therapeutic approach to affected patients, and for the development of health strategies aimed at the prevention and treatment of medical complications in the context of this disease. Based on the evaluation of 13 studies, an overall risk of 3.53 was obtained. (95\% CI: 2.79-4.47; p $<0.001)$ of suffering from COVID-19 with severe presentation, in patients with diabetes mellitus. [12]

In the United States, within the population over 64 years of age, considered the highest risk for dying from COVID19 , almost $27 \%$ have diabetes mellitus. Another study 
carried out in patients with diabetes mellitus and COVID19 showed that $69 \%$ had elevated capillary glucose monitoring values and $10 \%$ had at least one episode of hypoglycemia. On the other hand, it has been postulated that pancreatic tissue could be affected by viral infection, with the consequent alteration of hydrocarbon metabolism. Last but not least, the anxiety state described in patients with SARS-Cov-2 infection in the patient with diabetes could worsen hyperglycemia. Patients with diabetes usually have other comorbidities such as hypertension, chronic obstructive pulmonary disease, coronary heart disease, cerebrovascular disease, chronic kidney disease, which makes them an extremely vulnerable population to present a severe disease due to COVID 19 and a high risk of hospitalization in ICU and death. [19]

The effects of COVID-19 on the endocrine system are not yet well established; however, individuals with diabetes mellitus (DM) who suffer from COVID-19 have a higher fatality rate (between $10 \%$ and $11 \%$ ), which establishes that $\mathrm{DM}$ is a risk factor for fatal outcomes among those who suffer from COVID-19. [20]

There are several hypotheses that could explain why these patients have a higher incidence and severity. It is well known that the person with DM2, per se, has a greater risk of infection, mainly due to a defect in innate immunity that affects phagocytosis, neutrophil chemotaxis and cellular immunity, which makes them especially vulnerable. It is also true that the high frequency of DM2, in severe cases of COVID-19, could simply reflect the higher prevalence of DM2 in the elderly, in addition to the fact that these patients also have more comorbidities, including cardiovascular disease. Therefore, despite the fact that respiratory symptoms are predominant in COVID-19 infection, DM2 takes on a special interest in this disease: both the risk of virus infection and its severity increase in these patients. [21]

The next question that arises is what mechanisms could connect COVID-19 infection with endocrine system disruption. The virus enters the cell using angiotensin converting enzyme 2 (ACE2) as a receptor, a membrane exopeptidase present mainly in the kidney, lungs and heart, but also in other organs, such as endothelial cells and the pancreas. [21]

Cardiovascular disease and diabetes are the most frequent comorbidities among those hospitalized. Fatality According to the series published by the Chinese CDC, with a total of 1,023 deaths among confirmed cases $(44,672)$, the crude fatality was $2.3 \%$. Patients who did not present comorbidities had a lower case fatality rate (around $0.9 \%$ ), compared to patients with comorbidities who had much higher rates (10.5\%). [22]

\section{Conclusions}

According to what has been reviewed, arterial hypertension and diabetes mellitus are the main pathologies that cause aggravation of patients diagnosed with covid 19. These diseases are the first causes of transfer to intensive care units. Cuba carries out continuous research work in which it has identified its vulnerable patients by health zones, maintaining their protection.

\section{References}

[1] Dominguez AN, Valdéz A. COVID-19. Cardiologist's point of view. Cuban Journal of Cardiology and Cardiovascular Surgery. 2020; 26 (1): 951. available at: http://revcardiologia.sld.cu/index.php/revcardiologia/article/do wnload/951/pdf

[2] Parra-Izquierdo V, Flórez-Sarmiento C, García del Risco F, Romero-Sánchez C. Gastrointestinal symptoms in COVID-19 disease and their implications in Inflammatory Bowel Disease. Colombian Journal of Gastroenterology. 2020; 35: 45-55. Available at: http://www.scielo.org.co/pdf/rcg/v35s1/01209957-rcg-35-s1-00045.pdf

[3] FROM TOMÁS JFÁ. CORONAVIRUS COVID-19; PATHOGENESIS, PREVENTION AND TREATMENT. available at: https://ebevidencia.com/wpcontent/uploads/2020/03/CORONAVIRUS-COVID-194\%C2\%AA-Ed-18.03.2020.pdf

[4] Bermejo PM, Ledo MJV, Rodríguez WB, Jo AHS, Díaz RG, Bravo VN. Fight against epidemic in COVID-19 in Cuba. Organization of epidemiological research. Journal of Scientific Information for the Health Directorate INFODIR. 2020 (32). Available at: http://www.revinfodir.sld.cu/index.php/infodir/article/downloa $\mathrm{d} / 831 / 1058$

[5] Cubadebate http://www.cubadebate.cu/noticias/

[6] Alais E. UPDATE ON COVID-19 AND LOOK FROM THE CYSTIC FIBROSIS. Available at: https://www.aamr.org.ar/secciones/coronavirus/covid_y_fq_20 20_fin1.pdf

[7] Prínce A, Claro J, Salabert Tortoló I, Alfonso Salabert I, Morales Díaz M, García Cruz D, et al. High blood pressure: an international health problem. Electronic Medical Journal. 2017; $39 \quad$ (4): $987-94 . \quad$ Available at: https://www.medigraphic.com/pdfs/revmedele/me2017/me174m.pdf

[8] Alarcón IV, Gutiérrez MdCJ. Mexico: chronic degenerative diseases (diabetes mellitus and hypertension) and vulnerability to COVID-19. Available at: https://www.researchgate.net/profile/Iliana_Alarcon/publicatio n/341625708_Mexico_las enfermedades_cronico_degenerati vas_diabetes_mellitus_e_hipertension_arterial_y_la_vulnerabi lidad ante el COVID-19/1inks/5ecc15 $\mathrm{c} 94585$ cabetes-relatedMexico-Diabetes-Certification-MexicoDiabetes-MelDiabetes-MexicoDelivery-ecc15c945-856Diabetes vulnerability-to-COVID-19.pdf

[9] del Busto JEB, Castellón RL, Pedroso MDM. Cerebrovascular disease and COVID-19. Annals of the Cuban Academy of $\begin{array}{llll}\text { Sciences. } \quad 2020 ; & 10 & \text { (2). Available at: }\end{array}$ $\mathrm{http} / / /$ revistaccuba.sld.cu/index.php/revacc/article/download/8 $02 / 833$

[10] Guzmán JT. The renin angiotensin aldosterone system, system inhibitor drugs, and COVID-19. Academic Record. 2020; 66 (May): 101-8. Available at: http://revista.uaca.ac.cr/index.php/actas/article/download/344/ 335 
[11] AADYND GDE, KIDNEY NY. COVID-19 PANDEMIC EMERGENCY. Available at: http://www.aadynd.org.ar/descargas/archivos/rion-aadyndpara-hd-en-emeregencia-covid19--mayo-2020.pdf

[12] Thais María PU, Raúl AR, Luis AM, editors. HYPERTENSION, DIABETES AND CHRONIC KIDNEY DISEASE AS RISK FACTORS FOR SERIOUS COVID-19. I Virtual Congress of Basic Biomedical Sciences of Granma; at: http://cibamanz2020.sld.cu/index.php/cibamanz/cibamanz202 0/paper/view/496/267

[13] Martínez JAP. Considerations for Cardiologists on the Frontline of COVID-19 Care. Cuban Journal of Cardiology and Cardiovascular Surgery. 2020; 26 (2): 996. Available at: http://revcardiologia.sld.cu/index.php/revcardiologia/article/do wnload/996/pdf

[14] Salazar MG, Espeche WG, Barochiner J, Leiva C, Ennis IL. Argentine Society of Arterial Hypertension. Available at: http://www.saha.org.ar/files/documents/Comunicado-saha-4de-mayo.pdf

[15] Martínez PH, Villaquirán C, Preciado CC, García OM, Gómez MB. Report-COVID-19. Universitas Médica. 2020; 61 (3). Available at: https://revistas.javeriana.edu.co/index.php/vnimedica/article/d ownload/29781/24214/
[16] Muñoz CAV, Romero M. Level of knowledge about diabetes and metabolic control of type 2 diabetic patients in the Medical Clinic Department of the Pasteur Clinic in Neuquén, Argentina, from February to April 2018. University Research Journal in health. 2019; 1 (1): 23-32.

[17] Alarcón IV, Gutiérrez MdCJ. Mexico: chronic degenerative diseases (diabetes mellitus and hypertension) and vulnerability to COVID-19.

[18] Pérez B. Coronavirus and diabetes. Rev chil endocrinol diabetes. 2020: 41.

[19] Cordo CS, Pagotto V, Cean P, Salzberg S. DIABETES AND COVID-19: CURRENT PHARMACOLOGICAL TREATMENTS.

[20] Vargas-Uricoechea H. COVID-19 in Colombia and herd immunity: is it time to consider it? Colombian Journal of Endocrinology, Diabetes \& Metabolism. 2020; 7 (1): 57-9.

[21] Pérez-Martínez P, Sánchez FC, Gómez JC, Gómez-Huelgas R. SOLVING ONE OF THE PIECES OF THE PUZLE: COVID19 AND TYPE 2 DIABETES. Revista Clínica Española. 2020.

[22] Service Murciano of Health and Service Prevention of Occupational Risks. Procedure for the protection of the health of workers with special vulnerability and sensitivity to COVID-19. 2020. 